\title{
Editorial
}

\section{Yeast Biotechnology 4.0}

\author{
Ronnie G. Willaert ${ }^{1,2}$ (D)
}

1 Research Group Structural Biology Brussels, Vrije Universiteit Brussel, 1050 Brussels, Belgium; Ronnie.Willaert@vub.be; Tel.: +32-2-629-18-46

2 International Joint Research Group VUB-EPFL NanoBiotechnology \& NanoMedicine (NANO), Vrije Universiteit Brussel, 1050 Brussels, Belgium

Keywords: yeast biodiversity; yeasts in snails; Saccharomyces cerevisiae diversity in spontaneous wine fermentations; CRISPR/Cas9 for wine yeasts; Treixadura wine fermentation; ochratoxin A adsorption on wine yeasts; coffee yeast fermentation; isocitric acid production by Yarrowia lipolytica; dengue antigen protein production in Pichia pastoris; lipolytic enzyme production by Candida cylindracea

\section{Yeast Biotechnology 4.0}

This Special Issue is a continuation of the first, second, and third "Yeast Biotechnology" Special Issue series of the journal Fermentation (MDPI). This issue compiles the current stateof-the-art of research and technology in the area of "yeast biotechnology" and highlights prominent current research directions in the fields of yeast biodiversity and fermentation, wine yeasts and wine fermentation, coffee and yeasts, and yeasts as a cell factory. We very much hope that you enjoy reading it and are looking forward to the next Special Issue "Yeast Biotechnology 5.0" scheduled to appear in 2021-2022.

\section{Yeast Biodiversity and Fermentation}

Yeasts have been associated with various insects [1]; e.g., Saccharomyces cerevisiae interact with wasps [2] or Drosophila [3], and Ashbya gossypii interacts with stinging-sucking insects (Heteroptera) [4,5]. Insects play an important role in the dispersal of yeasts to new habitats as well as in breeding and the provision of overwintering opportunities. Akan et al. [6] investigated the potential role of European terrestrial snails Cepaea hortensis and C. nemorales in yeast ecology since these snails are often found in association with human settlements and gardens. They found various yeast genera, including species frequently isolated from grape must, such as Hanseniaspora, Metschnikowia, Meyerozyma, and Pichia. The fermentation performance of the strains $H$. uvarum, Meyerozyma guilliermondii, and $P$. kudrivzevii in grape must highlighted their potential to contribute to novel beverage fermentations. However, several human pathogenic yeasts were also isolated, such as Candida albicans and C. lusitaniae. with regard to jurisdictional claims in published maps and institutional affiliations.

\section{Wine Yeasts and Wine Fermentation}

Over the last decades, new genetically engineered wine strains have been developed in laboratories. These newly developed strains are characterized by better fermentation abilities and improved sensory quality of wines, and are produced with the aim of targeting specific consumers. However, only two genetically modified wine yeast strains were recently registered and approved for commercial use. The recent CRISPR/Cas9 method shows great potential in engineering new strains to improve wine flavor and safety. These aspects are discussed in the review conducted by Vilela [7].

The dynamics of yeast strains during spontaneous beverage fermentations determine the final and sensory characteristics. Castrillo et al. [8] evaluated the diversity of S. cerevisiae strains in several organic wineries in the Galicia region (Spain) during 2013, 2014, and 2015 campaigns. A total of 66 different strains were identified using the mDNA-RFLPs 
method. Some strains showed a wide distribution and appeared in several wineries, and some strains were only identified in a specific winery.

The autochthonous $S$. cerevisiae strains XG3 has been isolated from spontaneous wine fermentations in the region around Galicia. It has been shown that this strain excelled in fermentative vigor and has positive effects on the chemical and sensory characteristics of the wines produced from the white cultivars at the laboratory and pilot scale $[9,10]$. Here, Blanco et al. [11] applied this strain for the production of Treixadura wine at an industrial scale. The Galician Treixadura is one of the main traditional white cultivars that is characterized by fruity and floral descriptors due to high concentrations of ethyl esters and volatile acids [12]. The study compared the produced wines by $S$. cerevisiae XG3 with those produced with a commercial yeast and spontaneous fermentation in three wineries. A sensory analysis showed that wines from XG3 allowed for the differentiation of them from the other Treixadura wines due to a higher total acidity; lower alcohol; and significantly higher concentrations of acetates, volatile acids, esters, and volatile phenols.

Ochratoxin A (OTA) is a mycotoxin that has been detected in several foods and beverages, such as bread, coffee, dried wine fruits, beer, grape juice, and wine [13-15]. Since OTA at high concentrations shows carcinogenic, nephrotoxic, and teratogenic effects [15], it is considered a principle safety hazard in the wine-making process [16]. Pulvirenti et al. [17] made a very large selection of wine yeasts that were derived from Portuguese, Spanish, and Italian fermenting musts of different cultivars, and screened this collection for the adsorption activity of OTA since this could reduce the OTA concentration in wine. They also screened for the adsorption capacity of pigments and phenolics since these compounds should not be removed from wine. They were able to select 10 strains with the desired absorption capacities that can be considered as good candidates for wine starters and have the potential to be used in yeast breeding programs.

\section{Yeasts and Coffee Fermentation}

Coffee is one of the most consumed beverages in the world. S. cerevisiae is mainly used in the fermentation of coffee, although various yeast species (besides Saccharomyces) from different genera, including Pichia, Candida, and Torulaspora, have been isolated during coffee processing steps [18,19]. Ruta and Farcasanu [20] reviewed the yeasts involved in coffee fermentation and focused on two aspects: (1) the role of yeasts in postharvest processing, the possibilities to use them as starter cultures for controlled fermentation, and their impact on the sensorial quality of processed coffee; (2) the potential use to capitalize on coffee wastes.

\section{Yeasts as Cell Factory}

Isocitric acid (ICA) and its derivatives are widely used as surfactants, detergents, and ion chelators to produce pharmaceutical products and cosmetics, as well as biologically active additives for food products [21,22]. The microbiological production of ICA is more advantageous for these applications since only the natural isomer threo- $D_{S}$ is produced. To increase the production by fermentation, Kamzolova et al. [23] firstly screened 30 taxonomically different yeast strains for their ICA yield, which resulted in the selection Yarrowia lipolytica VKM Y-2373. The fermentation yield could be further increased by cultivating this strain under nitrogen deficiency conditions with the addition of $1.5 \mathrm{mg} / \mathrm{L}$ iron to activate aconitate hydratase and $30 \mathrm{mM}$ itaconic acid, which blocks the conversion of isocitrate at the level of isocitrate lyase.

The dengue virus is a major arbovirus that affects many humans, with 2.1 million cases being reported in the Americas alone by the World Health Organization for 2016 [24]. To develop diagnostic kits for the rapid detection of the virus, it is essential to produce the antigens at large scale. Teixeira et al. [25] developed a method to produce the prM/M and E proteins of dengue virus-3 using the yeast Pichia pastoris as an efficient cell factory. The proteins were secreted in the medium of the culture and could subsequently be easily purified by ammonium sulfate precipitation. 
The yeast genus Candida is widespread in nature where they can be found in humid conditions, rich in organic compounds such as organic acids and ethanol. Some Candida species (mainly C. albicans, C. glabrata, C. tropicalis, and C. parapsilosis) are the most common causes of fungal infection [26]. However, many Candida yeasts can be useful in various biotechnological processes since they can produce commercially and industrially important enzymes. For example, C. cylindracea is of great interest due to its ability to produce lipolytic enzymes and its potential use in the production of food and pharmaceuticals [27,28]. Zieniuk et al. [29] evaluated the effect of several lipid-rich food industry wastes in culture medium on the growth of C. cylindracea DSM 2031, as these wastes can be used to increase biomass yield and increase the production of lipolytic enzymes. It was shown that the use of waste substrates may contribute to reducing the costs of commercial production, and such a solution is part of the sustainable development strategy.

Acknowledgments: The Belgian Federal Science Policy Office (Belspo) and the European Space Agency (ESA) PRODEX program supported this work. The Research Council of the Vrije Universiteit Brussel (Belgium) and the University of Ghent (Belgium) are acknowledged to support the Alliance Research Group VUB-UGhent NanoMicrobiology (NAMI), and the International Joint Research Group (IJRG) VUB-EPFL BioNanotechnology and NanoMedicine (NANO).

Conflicts of Interest: The author declares no conflict of interest.

\section{References}

1. Stefanini, I. Yeast-insect associations: It takes guts. Yeast 2018, 35, 315-330. [CrossRef] [PubMed]

2. Stefanini, I.; Dapporto, L.; Legras, J.L.; Calabretta, A.; Di Paola, M.; De Filippo, C.; Viola, R.; Capretti, P.; Polsinelli, M.; Turillazzi, S.; et al. Role of social wasps in Saccharomyces cerevisiae ecology and evolution. Proc. Natl. Acad. Sci. USA 2012, 109, 13398-13403. [CrossRef]

3. Christiaens, J.F.; Franco, L.M.; Cools, T.L.; de Meester, L.; Michiels, J.; Wenseleers, T.; Hassan, B.A.; Yaksi, E.; Verstrepen, K.J. The fungal aroma gene ATF1 promotes dispersal of yeast cells through insect vectors. Cell Rep. 2014, 9, 425-432. [CrossRef]

4. Walther, A.; Wendland, J. Yap1-dependent oxidative stress response provides a link to riboflavin production in Ashbya gossypii. Fungal Genet. Biol. 2012, 49, 697-707. [CrossRef]

5. Dietrich, F.S.; Voegeli, S.; Kuo, S.; Philippsen, P. Genomes of ashbya fungi isolated from insects reveal four mating-type loci, numerous translocations, lack of transposons, and distinct gene duplications. G3 Genes Genomes Genet. 2013, 3, $1225-1239$. [CrossRef]

6. Akan, M.; Michling, F.; Matti, K.; Krause, S.; Muno-Bender, J.; Wendland, J. Snails as Taxis for a Large Yeast Biodiversity. Fermentation 2020, 6, 90. [CrossRef]

7. Vilela, A. An Overview of CRISPR-Based Technologies in Wine Yeasts to Improve Wine Flavor and Safety. Fermentation 2021, 7, 5. [CrossRef]

8. Castrillo, D.; Neira, N.; Blanco, P. Saccharomyces cerevisiae Strain Diversity Associated with Spontaneous Fermentations in Organic Wineries from Galicia (NW Spain). Fermentation 2020, 6, 89. [CrossRef]

9. Blanco, P.; Mirás-Avalos, J.M.; Suárez, V.; Orriols, I. Inoculation of Treixadura musts with autochthonous Saccharomyces cerevisiae strains: Fermentative performance and influence on the wine characteristics. Food Sci. Technol. Int. 2013, 19, 177-186. [CrossRef]

10. Bouzas-Cid, Y.; Falqué, E.; Orriols, I.; Mirás-Avalos, J.M. Effects of irrigation over three years on the amino acid composition of Treixadura (Vitis vinifera L.) musts and wines, and on the aromatic composition and sensory profiles of its wines. Food Chem. 2018, 240, 707-716. [CrossRef] [PubMed]

11. Blanco, P.; Vázquez-Alén, M.; Garde-Cerdán, T.; Vilanova, M. Application of Autochthonous Yeast Saccharomyces cerevisiae XG3 in Treixadura Wines from D.O. Ribeiro (NW Spain): Effect on Wine Aroma. Fermentation 2021, 7, 31. [CrossRef]

12. Falqué, E.; Fernández, E.; Dubourdieu, D. Volatile components of Loureira, Dona Branca, and Treixadura wines. J. Agric. Food Chem. 2002, 50, 538-543. [CrossRef] [PubMed]

13. Mateo, R.; Medina, Á.; Mateo, E.M.; Mateo, F.; Jiménez, M. An overview of ochratoxin A in beer and wine. Int. J. Food Microbiol. 2007, 119, 79-83. [CrossRef]

14. Bellí, N.; Marín, S.; Duaigües, A.; Ramos, A.J.; Sanchis, V. Ochratoxin A in wines, musts and grape juices from Spain. J. Sci. Food Agric. 2004, 84, 591-594. [CrossRef]

15. Varga, J.; Rigó, K.; Téren, J.; Mesterházy, Á. Recent advances in ochratoxin research I. Production, detection and occurrence of ochratoxins. Cereal Res. Commun. 2001, 29, 85-92. [CrossRef]

16. Fiori, S.; Urgeghe, P.P.; Hammami, W.; Razzu, S.; Jaoua, S.; Migheli, Q. Biocontrol activity of four non- and low-fermenting yeast strains against Aspergillus carbonarius and their ability to remove ochratoxin A from grape juice. Int. J. Food Microbiol. 2014, 189, 45-50. [CrossRef] [PubMed] 
17. Pulvirenti, A.; De Vero, L.; Blaiotta, G.; Sidari, R.; Iosca, G.; Gullo, M.; Caridi, A. Selection of Wine Saccharomyces cerevisiae Strains and Their Screening for the Adsorption Activity of Pigments, Phenolics and Ochratoxin A. Fermentation 2020, 6, 80. [CrossRef]

18. De Bruyn, F.; Zhang, S.J.; Pothakos, V.; Torres, J.; Lambot, C.; Moroni, A.V.; Callanan, M.; Sybesma, W.; Weckx, S.; De Vuyst, L. Exploring the impacts of postharvest processing on the microbiota and metabolite profiles during green coffee bean production. Appl. Environ. Microbiol. 2017, 83. [CrossRef]

19. Evangelista, S.R.; da Cruz Pedrozo Miguel, M.G.; de Souza Cordeiro, C.; Silva, C.F.; Marques Pinheiro, A.C.; Schwan, R.F. Inoculation of starter cultures in a semi-dry coffee (Coffea arabica) fermentation process. Food Microbiol. 2014, 44, 87-95. [CrossRef]

20. Ruta, L.L.; Farcasanu, I.C. Coffee and Yeasts: From Flavor to Biotechnology. Fermentation 2021, 7, 9. [CrossRef]

21. Heretsch, P.; Thomas, F.; Aurich, A.; Krautscheid, H.; Sicker, D.; Giannis, A. Syntheses with a Chiral Building Block from the Citric Acid Cycle: (2R,3S)-Isocitric Acid by Fermentation of Sunflower Oil. Angew. Chemie Int. Ed. 2008, 47, 1958-1960. [CrossRef] [PubMed]

22. Kamzolova, S.V.; Morgunov, I.G. Microbial production of (2R,3S)-isocitric acid: State of the arts and prospects. Appl. Microbiol. Biotechnol. 2019, 103, 9321-9333. [CrossRef]

23. Kamzolova, S.V.; Samoilenko, V.A.; Lunina, J.N.; Morgunov, I.G. Effects of Medium Components on Isocitric Acid Production by Yarrowia lipolytica Yeast. Fermentation 2020, 6, 112. [CrossRef]

24. Dengue and Severe Dengue. Available online: https://www.who.int/news-room/fact-sheets/detail/dengue-and-severe-dengue (accessed on 26 April 2021).

25. Teixeira, M.D.O.; Dias, R.S.; Prates, J.W.O.; Monteiro, J.M.C.; Xisto, M.F.; da Silva, C.C.; De Paula, S.O. Production of Proteins prM/M and E of Dengue Virus-3 in Pichia pastoris: Simplified Purification and Evaluation of Their Use as Antigens in Serological Diagnosis of Dengue. Fermentation 2020, 6, 88. [CrossRef]

26. Turner, S.A.; Butler, G. The Candida pathogenic species complex. Cold Spring Harb. Perspect. Med. 2014, 4, a019778. [CrossRef]

27. Kim, B.S.; Hou, C.T. Production of lipase by high cell density fed-batch culture of Candida cylindracea. Bioprocess Biosyst. Eng. 2006, 29, 59-64. [CrossRef] [PubMed]

28. Belkacemi, F.Z.; Merabet-Khelassi, M.; Aribi-Zouioueche, L.; Riant, O. Production of l-menthyl acetate through kinetic resolution by Candida cylindracea lipase: Effects of alkaloids as additives. Res. Chem. Intermed. 2018, 44, 6847-6860. [CrossRef]

29. Zieniuk, B.; Mazurczak-Zieniuk, P.; Fabiszewska, A. Exploring the Impact of Lipid-Rich Food Industry Waste Carbon Sources on the Growth of Candida cylindracea DSM 2031. Fermentation 2020, 6, 122. [CrossRef] 